\title{
Assessing the representativeness of durability tests for wood pellets by DEM Simulation - Comparing conditions in a durability test with transfer chutes
}

\author{
Aditya Mahajan ${ }^{1}$, Ioannis Dafnomilis ${ }^{2}$, Victoria Hancock $^{2}$, Gabriel Lodewijks ${ }^{2}$ and Dingena Schott $^{2,}{ }^{,}$ \\ ${ }^{1}$ Indian Institute of Technology Delhi, Department of Mechanical Engineering, Hauz Khas, New Delhi, India - 110016 \\ ${ }^{2}$ TU Delft, Department of Maritime and Transport Technology, 2628 CD Delft, The Netherlands
}

\begin{abstract}
Dust generation when handling wood pellets is related to the durability of the product, in other words the wear rate of particles subject to forces. During transport, storage and handling wood pellets undergo different forces when interacting with different pieces of equipment.

This paper assesses the representativeness of the tumbling can test in relation to transfer chutes, by comparing forces acting on wood pellets in durability tests and in transfer chutes using DEM. The study also incorporates effects such as shape and size variations. The results showed that the tumbling can test underestimates compressive and tangential forces. Since the tested material is subject to milder conditions than in reality, it can be concluded that this test is not representative for the conditions in the supply chain of wood pellets.
\end{abstract}

\section{Introduction}

Over the years a standard for wood pellets (EN15210 or ISO/NP17831-1) [1] has been developed to assess the durability of materials amongst others applied to wood pellets, such as a tumbling can. However, it is unlikely that this is representative for the handling in the whole supply chain because real operational conditions can greatly differ in terms of forces from tests on lab-scale as is suggested by previous work on the topic comparing durability tests to filling and reclaiming of silos [2]. Moreover, in the biomass industry the problem of dust generation and generation of fines (crumbling off of smaller parts of the pellets) remains, despite a standard being in place.

This paper assesses the representativeness of the tumbling can test in relation to transfer chutes, by comparing forces acting on wood pellets in durability tests and in five transfer chutes using DEM. In addition the effect of the particle composition of a wood pellet is investigated.

\section{Materials and Methods}

\subsection{DEM simulations}

Discrete Element Method [3] is a numerical technique to analyse the movement and interaction of multiple small bodies in a system. In this paper EDEM 2.6.1 [4] has been used as the DEM simulation software.

\subsubsection{Materials: Pellet Models}

Wood pellets are cylindrical shaped particles of varying length. They are created by compressing smaller wood particles together in a pellet mill. Here $12 \mathrm{~mm}$ wood pellets are considered.

For the simulations 3 different pellet shapes were used. The shape variation is shown in Figure 1.

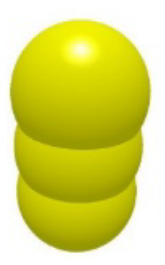

a)
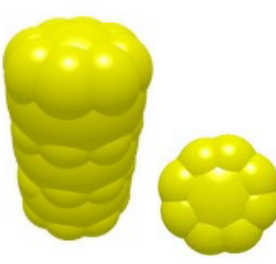

b)

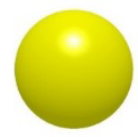

c)
Figure 1: Pellet Models a) Simple Particle (3 spheres) b) Advanced Shape (35 spheres) c) Sphere Equivalent

The equivalent sphere diameter $\left(D_{\text {eq }}\right)$ of shape c) was calculated using :

$$
\mathrm{D}_{e q}=2 \sqrt[3]{\frac{3}{4} \frac{V_{\text {pellet }}}{\pi}}
$$

For shape a) and b) 3 different lengths were defined. The size distribution follows a total mass ratio of $4: 3: 3$ for the $22 \mathrm{~mm}, 30 \mathrm{~mm}$ and $18 \mathrm{~mm}$ pellet lengths respectively. An overview of particle shapes and size distribution is given in Table 1. 
Table 1: Size and size distribution for for the 3 different particle shapes simulated with a tumbling can.

\begin{tabular}{|c|c|c|c|c|c|c|}
\hline \multirow{2}{*}{$\begin{array}{c}\begin{array}{c}\text { Para- } \\
\text { meters }\end{array} \\
\mathrm{D}(\mathrm{mm})\end{array}$} & \multirow{2}{*}{ 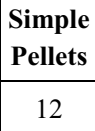 } & \multirow{2}{*}{$\begin{array}{c}\begin{array}{c}\text { Advanced } \\
\text { Pellets }\end{array} \\
12\end{array}$} & \multicolumn{3}{|c|}{$\begin{array}{c}\text { Simple Pellets } \\
\text { with size distribution }\end{array}$} & \multirow{2}{*}{$\begin{array}{c}\begin{array}{c}\text { Sphere } \\
\text { equivalent }\end{array} \\
15.568\end{array}$} \\
\hline & & & 12 & 12 & 12 & \\
\hline $\mathrm{L}(\mathrm{mm})$ & 22 & 22 & 22 & 30 & 18 & - \\
\hline $\begin{array}{l}\text { Particle } \\
\text { mass }(g)\end{array}$ & 2.74 & 2.8 & 2.74 & 3.55 & 2.18 & 2.8 \\
\hline \multirow{2}{*}{$\begin{array}{l}\text { Number } \\
\text { of } \\
\text { pellets }\end{array}$} & \multirow[b]{2}{*}{182} & \multirow[b]{2}{*}{179} & 73 & 42 & 68 & \multirow[b]{2}{*}{179} \\
\hline & & & \multicolumn{3}{|c|}{ Total 183} & \\
\hline
\end{tabular}

For shapes a) 3 spheres and b) 35 spheres, two different contact models were applied: Hertz-Mindlin no-slip and Hertz-Mindlin with bonding. This means that the spheres are flexibly bonded together instead of a rigid connection. This gives a total of 7 different pellet models tested.

\subsection{Calibration}

In order to ensure realistic behaviour of the particles inside the tumbling can and the transfer chutes, the material model will be calibrated with 3 laboratory tests; the bulk density test, the lifting can test and the ledge test.

The particle density was measured by putting a sample of $100 \mathrm{~g}$ in a measuring cylinder filled with water. The volume was determined by the immediate increase of the water level, which indicates that minimum water is absorbed and the particle density is unaffected.

The ledge test is a box open at the top (Figure 2a). Two faces are made of wood and the rest is made of transparent acrylic. One wooden face is latched and hinged at the upper end. The inner height is $26 \mathrm{~cm}$, the door is $20 \mathrm{~cm}$ and the viewing acrylic walls are $22 \mathrm{~cm}$ wide. First, the box is filled with pellets up to an approximate height of $14-15 \mathrm{~cm}$ from the base. Then the door is unlatched and the material flows out until it reaches a certain angle of repose which was noted down. This was repeated 20 times.

The lifting can test is a cylinder open at both ends of $20 \mathrm{~cm}$ height and $26 \mathrm{~cm}$ diameter, i.e. more than 20 times the diameter of the sample pellet. The can is put on a base and then filled by pouring in pellets from the top until it is filled up to a height of $14-15 \mathrm{~cm}$. It is then lifted vertically and material escapes out from the bottom and spreads on the base resulting in formation of a pile (Figure 2b). The slope of this pile is measured from 5 different directions. This is repeated thrice, leading to 15 observations.

After determining the mean and standard deviation of the observations, the upper and lower limit values of the $95 \%$ confidence interval were obtained for the sample.

These tests will be simulated with DEM as well. For that, different combinations of parameters were tested and the results compared to the experimental results.
After a number of iterations a calibrated model was achieved.

Since the value of the coefficient of static friction (wood-wood) in general lies between 0.2-0.5 and the rolling friction coefficient lies between 0-0.05 [5][6], the possible combinations were tested within this range.

Once calibrated, the model will then be used in simulations with the tumbling can test and the transfer chutes.

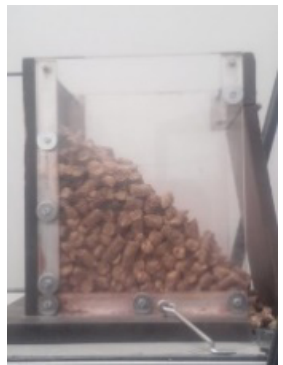

a)

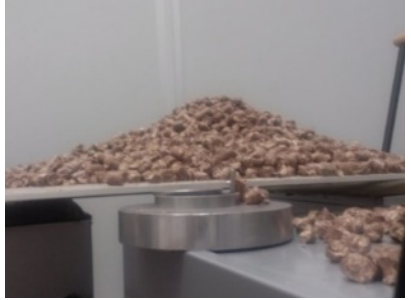

b)
Figure 2: a) Ledge test, b) Pile formed after lifting can test

\subsection{Tumbling can test}

The tumbling can or rotating drum (Figure 3 ) is a test device with which the durability of wood pellets is determined under mechanical handling conditions. Other durability testers, such as the Holmen durability tester and the Ligno tester focus on the pneumatic handling of pellets. Compared to the tumbling can, both testers operate in a smaller time frame, where the pellets are exposed to higher destructive forces [7]. Nevertheless, according to Temmerman et al. [8] more repeatable and reproducible results are achievable with the tumbling can compared to the Ligno tester.

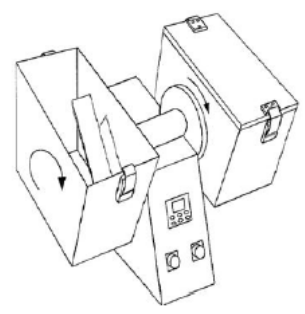

Figure 3 Tumbling can tester for pellet durability test according to EN15210-1

A single chamber of the tumbling can was modelled according to the EN15210 standard [1] as a stainless steel box of dimensions $0.3 \times 0.3 \times 0.125 \mathrm{~m}$. Inside a stainless steel baffle of $0.23 \times 0.05 \mathrm{~m}$ is mounted to one side. The amount of material $(500 \mathrm{~g})$ and operating conditions (constant rotational speed of $50 \mathrm{rpm}$ ) were as described in the standard procedure. In practice the result is the mechanical durability derived from the measured number of fines created in the test due to breakage of particles as the result of forces acting on them. Here the forces are being used to compare to the conditions in the transfer chutes. The simulations were run for $30 \mathrm{sec}$ comprising 25 rotations. 


\subsection{Transfer chutes}

Five different transfer chute designs were compared: The Rockbox, Sloped chute, Hood only, Hood \& Spoon and Tralix are presented in Figure 4 and 5.

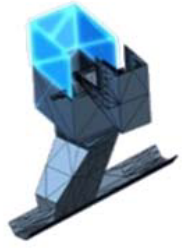

a)

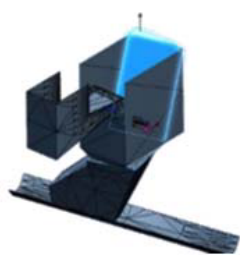

b)

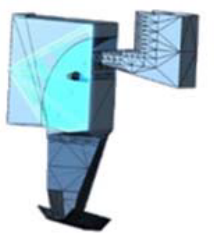

c)
Figure 4: a) Rockbox, b) Sloped Chute, c) Hood only

The Rockbox (Figure 4a) first fills to form a pile and after the pile attains a particular slope a regular material flow is generated. This layer of material then acts as a slope. As such the rockbox prevents damage of the equipment by sacrificing the biomass instead.

In a Sloped chute (Figure $4 \mathrm{~b}$ ) the material does not accumulate, instead the sloping face allows it to directly flow out to the receiving conveyor.

The Hood only model (Figure 4c) has a hood instead of a slope. The hood gives a smoother flow instead of abruptly stopping the particles.

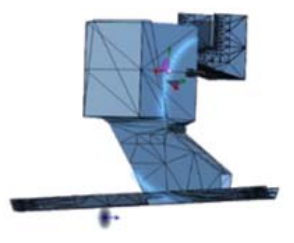

a)

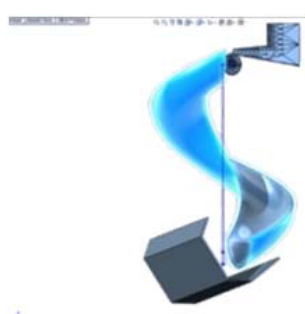

b)
Figure 5: a) Hood \& spoon, b) Tralix (transfer helix)

The Hood \& Spoon model (Figure 5a) is an upgraded version of the above model. It has an added curved (spoon) exit face to ensure smooth exit of particles to the output conveyor belt besides the smooth entry.

The Tralix (Transfer Helix) is depicted in Figure 5b and provides a helical path for particles to flow in a more streamlined and non-accumulative manner.

The modelled input and output belt speed was $4 \mathrm{~m} / \mathrm{s}$. The vertical distance between belts is $4.7 \mathrm{~m}$, except in helix where it is $11.2 \mathrm{~m}$. The mass flow is $1044 \mathrm{tph}$. The simulations were run twice with the simple pellet model (Figure 1a) and each took between 25 and 30 hours.

\section{Results}

\subsection{Calibrated material}

The angle of repose had a mean value of 41.1 degrees, standard deviation of 2.4 degrees $(95 \%$ confidence interval being 39.9-42.3 degrees) for the ledge test and a mean of 24.4 degrees, standard deviation of 2.4 degrees (95\% confidence interval being 23.1-25.7 degrees) for the lifting can test.
The angle of repose results obtained via simulations were matched to lie in the confidence interval of the experimental results and then ranked in order of closeness to the mean value, with the value closer to the mean having a higher rank. Then the data that qualified for both cases was checked by summing the ranks achieved in the 2 cases. The lower the sum, the closer the results are to the experiments.

From the analysis the coefficient of static and rolling friction was ascertained as 0.4 and 0.04 for $12 \mathrm{~mm}$ wood pellets. The full listing of DEM parameters is given in Table 2.

Table 2: DEM input parameters for wood pellets.

\begin{tabular}{|c|c|c|c|}
\hline Parameter & Value & Parameter & Value \\
\hline$\rho_{\mathrm{p}}\left[\mathrm{kg} / \mathrm{m}^{3}\right]$ & 1389 & $\rho_{\mathrm{w}}\left[\mathrm{kg} / \mathrm{m}^{3}\right]$ & 7800 \\
\hline $\mathrm{E}_{\mathrm{p}}[\mathrm{Pa}]$ & $1 \mathrm{e} 08$ & $\mathrm{E}_{\mathrm{w}}[\mathrm{Pa}]$ & $7 \mathrm{e} 10$ \\
\hline$v_{\mathrm{p}}$ & 0.1 & $v_{\mathrm{W}}$ & 0.3 \\
\hline $\mathrm{C}_{\mathrm{R}, \mathrm{p}}$ & 0.02 & $\mathrm{C}_{\mathrm{R}, \mathrm{w}}$ & 0.02 \\
\hline$\mu_{\mathrm{s}, \mathrm{p}-\mathrm{p}}$ & 0.4 & $\mu_{\mathrm{s}, \mathrm{p}-\mathrm{w}}$ & 0.4 \\
\hline$\mu_{\mathrm{r}, \mathrm{p}-\mathrm{p}}$ & 0.04 & $\mu_{\mathrm{r}, \mathrm{p}-\mathrm{w}}$ & 0.04 \\
\hline $\mathrm{D}_{\mathrm{p}}[\mathrm{mm}]$ & 12 & $\Delta \mathrm{t}[\mathrm{s}]$ & $1.73 \mathrm{e}-05$ \\
\hline \multicolumn{2}{|l|}{ If bonded: } & & \\
\hline Bonded disk radius & $6 \mathrm{~mm}$ & & \\
\hline Normal stiffness & $5 \mathrm{e} 6 \mathrm{~N} / \mathrm{m}^{3}$ & Critical normal stress & $4 \mathrm{e} 7 \mathrm{~Pa}$ \\
\hline Shear stiffness & $5 \mathrm{e} 6 \mathrm{~N} / \mathrm{m}^{3}$ & Critical shear stress & $2 \mathrm{e} 7 \mathrm{~Pa}$ \\
\hline
\end{tabular}

\subsection{Tumbling can test}

With the calibrated model, simulations of the tumbling can were performed for the various pellet models introduced in Section 2.1.1. The particle trajectories in the tumbling can are illustrated in Figure 6.

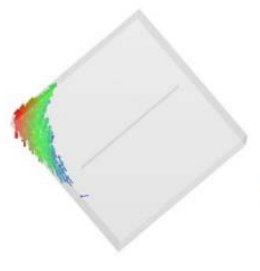

a)

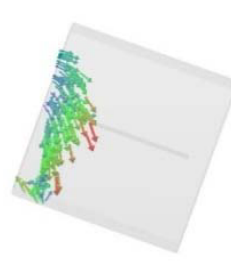

b)

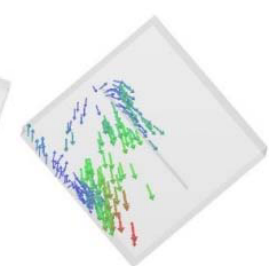

c)
Figure 6: Tumbling can particle trajectories at a) $t=1.5 \mathrm{~s}, \mathrm{~b}$ ) $\mathrm{t}=1.7 \mathrm{~s}$ and $\mathrm{c}) \mathrm{t}=1.8 \mathrm{~s}$

The forces acting on the particles during rotation of the can are analysed and the compressive force is depicted in Figure 7.

The advanced shape particle is at the higher end in all cases, i.e. when all are non-bonded models $\left(1^{\text {st }}\right.$ three series) and when all are bonded models (next three series). This is probably due to the fact that the advanced shape model has a more realistic shape, lesser vacant voids and since it is made of more spheres, it has a higher area of contact with the surroundings. The other shapes and sizes undergo slightly smaller compressive forces.

Also the pellets built with bonded contact models experience slightly higher compressive forces compared to their respective non-bonded counterparts. However, a 
significant effect of the pellet model on the average compressive forces could not be shown. From a comparison of tangential and compressive forces the average tangential force is lower by a factor of 6-7 (not shown here). It can be inferred that the tangential forces do not play a critical role compared to the compressive forces for the durability of particles.

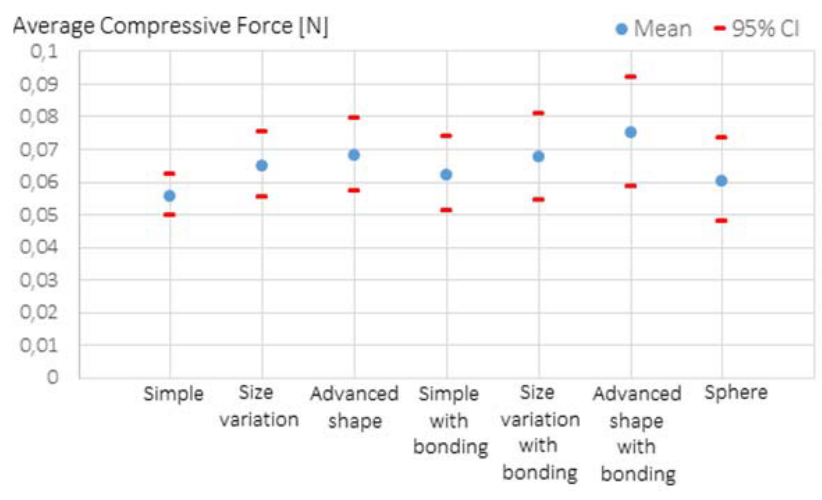

Figure 7: Average compressive force and the 95\% confidence intervals in the tumbling can for different pellet models.

The angular velocity analysis reveals how size variation leads to bigger size particles providing more gaps for the smaller particles to rotate and roll in, whereas the advanced shape provides indented surface leading to more friction and difficulty in rolling.

\subsection{Transfer chutes}

The average particle compressive force for the five different configurations of the transfer chutes is depicted in Figure 8.

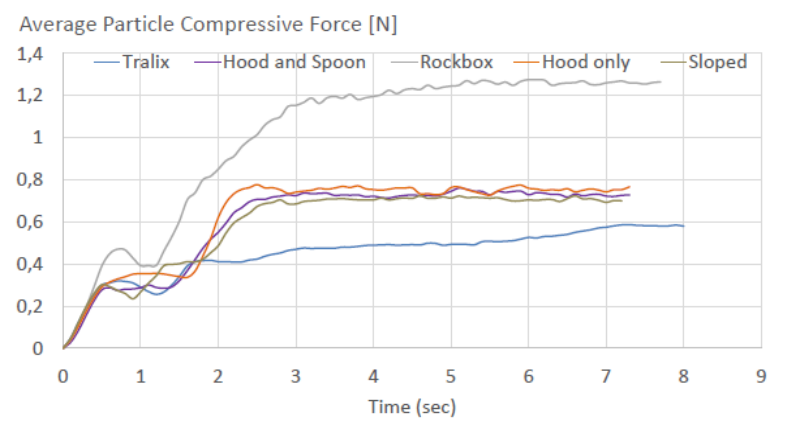

Figure 8: Average compressive force in the different chute configurations, steady state after $2.5 \mathrm{~s}$

The initial behaviour (up to $1.5 \mathrm{~s}$ ) is common as the particles are in the feeding conveyer and are about to enter the chutes. After that the difference can be seen among the different chutes. The hood \& spoon, the hood only and the sloped models have almost identical performance. After $2.5 \mathrm{~s}$ the particle forces in the transfer chutes reach a steady state except for the rockbox and the Tralix. For the rockbox, this is because the accumulation and initial heap formation takes more time. After the flow in the rockbox is established it can be seen that the average compressive force is almost twice the value of the other configurations. The Tralix is gentler as it carries the bulk down gradually in uncrowded flow instead of particles falling down and impacting.

The pattern for tangential forces (not shown here) is similar except that the tangential forces are 7-8 times smaller than the compressive forces. The values of the hood and spoon configuration are closer to the rockbox.

\section{Conclusions}

Based on the DEM simulation results in this paper the tumbling can cannot be considered as representative for the conditions in transfer chutes. From a comparison of forces acting on the particles it follows that the average compressive forces and tangential forces in the tumbling can are underestimated by a factor of 10-20. This is compared to a mass flow of 1044 tph and velocities of $4 \mathrm{~m} / \mathrm{s}$ which in industrial practice are often higher.

Several shapes and particle contact models of wood pellets were tested in the tumbling can. The advanced shape consists of 35 spheres and is most realistic in design due to greater contact area and sharper edges that greatly affect the particle dynamics. However, in the tumbling can simulation a significant difference in compressive and tangential forces could not be shown. In addition, a disadvantage of the advanced shape is the increase in computational times.

Five designs of transfer chutes under similar simulation conditions were compared. The Tralix has the lowest average compressive forces and the traditional rockbox is the worst in that aspect.

The durability testing mechanism should be changed to ensure a better representation of the actual supply chain conditions. The improved tests must subject the material to higher compressive and tangential forces.

\section{References}

[1] ISO/TC 238, Solid biofuels - Determination of mechanical durability of pellets and briquettes - Part 1: Pellets (2011)

[2] D.L. Schott, R. Tans, I. Dafnomilis, V. Hancock \& G. Lodewijks, On the durability tests for handling of solid biomass such as wood pellets, FME Transactions 44, 279-284 (2016)

[3] P.A. Cundall and O.D.L. Strack, A discrete numerical model for granular assemblies, Geotechnique, 29 (No. 1), 47-65, (1979)

[4] DEM Solutions, EDEM 2.6.1 (2014)

[5] R.L. Stroshine, Physical Properties of Agricultural Materials and Food Products (2004)

[6] http://www.engineeringtoolbox.com/frictioncoefficients-d 778.html

[7] Kaliyan N. and R.V. Morey, Factors affecting strength and durability of densified biomass products; Biomass and Bioenergy, 33, 337-359 (2009)

[8] Temmerman,M., F.Rabier, P.D.Jensen, H.Hartmann, Th.Böhm, Comparative study of durability test methods for pellets and briquettes; Biomass and Bioenergy 30, 964-972 (2006) 